\title{
Retraction Note to: The financial crisis research: a bibliometric analysis
}

\author{
Chien-Lung Hsu', ${ }^{1,2}$ Chun-Hao Chiang ${ }^{3}$
}

Published online: 3 August 2017

(C) Akadémiai Kiadó, Budapest, Hungary 2017

\section{Retraction Note to: Scientometrics (2015) 105:161-177 DOI 10.1007/s11192-015-1698-z}

The Editor-in-Chief has decided to retract the following article, Chien-Lung Hsu and Chun-Hao Chiang: The financial crisis research: a bibliometric analysis. Scientometrics 105, pp. 161-177, DOI 10.1007/s11192-015-1698-z.

Upon investigation carried out according to the Committee on Publication Ethics guidelines, it has been found that the article contains severe insufficiencies regarding the use of sources and replication of material (figures, tables and verbatim text) without attribution or with inappropriate quotation. The list of identified cases comprises the following sources.

- Ho, Scientometrics (2014) 98:137-155

- Bhanot et al., Journal of Banking \& Finance (2014) 38:51-63

- Mink \& de Haan, International Money and Finance (2013) 34:102-113

The online version of the original article can be found under doi:10.1007/s11192-015-1698-z.

Chun-Hao Chiang

uuuddd@hotmail.com; hector@megaholdings.com.tw

Chien-Lung Hsu

alanhsu8399@takming.edu.tw

1 Department of Marketing Management, Takming University of Science and Technology, No. 56, Section 1, Huanshan Road, Neihu, Taipei City 11451, Taiwan, ROC

2 Department of Banking and Finance, National Chi Nan University, No. 1, University Road, Puli, Nantou County 54561, Taiwan, ROC

3 Department of Risk Control Management, Mega Financial Holding Company, 14F, No. 123, Section 2, Jhongsiao E. Road, Taipei City 100, Taiwan, ROC 
- Wang \& Yao, Applied Economics (2014) 46:14, 1665-1676

- Tsai \& Yang (Journal of Medical Library Association (2005) 93(4):450-458

Further inconsistencies concern retrieval, management, and reporting of data resulting in irreplicability of figures and findings.

The authors have agreed on the retraction. 